\title{
EVALUATION OF THE EFFECTS OF ULTRA-LOW DOSE NALOXONE ON BRACHIAL PLEXUS BLOCK WITH BUPIVACAINE
}

\author{
Amit Sharma Bhattarai ${ }^{1^{*}}$, Gentle Sunder Shrestha ${ }^{2}$, Megha Koirala ${ }^{1}$, Pramesh Sunder Shrestha ${ }^{2}$, Moda Nath Marhatta ${ }^{3}$
}

\section{Affiliation}

1. Lecturer, Department of Anaesthesiology, Maharajgunj Medical Campus, Institute of Medicine, Nepal.

2. Associate Professor, Department of Anaesthesiology, Maharajgunj Medical Campus, Institute of Medicine, Nepal.

3. Professor, Department of Anaesthesiology, Nepalgunj Medical College, Nepal.

\section{ARTICLE INFO}

Received : 15 February, 2021
Accepted $: 13$ March, 2021
Published $: 15$ June, 2021

(c) Authors retain copyright and grant the journal right of first publication with the work simultaneously licensed under Creative Commons Attribution License CC - BY 4.0 that allows others to share the work with an acknowledgment of the work's authorship and initial publication in this journal.

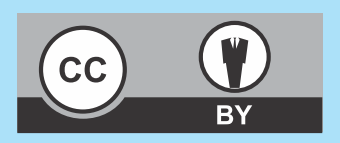

ORA 237

DOI: https://doi.org/10.3126/bjhs.v6i1.37640

\section{* Corresponding Author \\ Dr Gentle Sunder Shrestha Associate Professor \\ Department of Anaesthesiology} Maharajgunj Medical Campus, Institute of Medicine, Nepal ORCID: https://orcid.org/0000-0003-0385-2340

\section{Citation}

Amit Sharma Bhattarai, Gentle Sunder Shrestha, Megha Koirala, Pramesh Sunder Shrestha, Moda Nath Marhatta. Evaluation of the Effects of ultra-low dose Naloxone on Brachial Plexus block with bupivacaine. BJHS 2021;6(1)14.1373-1376.

\section{ABSTRACT}

\section{Introduction}

Adjuvants are used in conjunction with local anaesthetics for brachial plexus block to quicken onset, prolong duration and augment the quality of anaesthesia.

\section{Objectives}

The study aims to evaluate the effect of adding ultra-low dose naloxone to bupivacaine on the duration of postoperative analgesia.

\section{Methodology}

A prospective, randomized, double-blind study was conducted including forty American Society of Anesthesiologists Physical Status (ASA PS) I and II patients of either sex between 15 and 65 years of age scheduled for upper limb surgery. They were randomized into two groups. Group BN received a mixture of $0.33 \%$ plain bupivacaine with ultra-low dose naloxone (100 ng) and group BS received $0.33 \%$ plain bupivacaine with saline. The procedure was standardized in both groups. The onset of sensory and motor block were assessed with pinprick sensation and muscle power respectively. Visual Analogue Score (VAS) was used to assess the pain at 1, 2, 4, 8 and 12 hours postoperatively.

\section{Result}

The patients were comparable with respect to age, sex, ASA PS, baseline hemodynamic and respiratory parameters and duration of surgery. The mean duration of analgesia in group BN was significantly longer (610.7 \pm 125.4 mins) as compared to group BS (354.3 \pm 59.6 mins) $(p<0.001)$. No complications were noted in both the groups.

\section{Conclusion}

This study demonstrated that 100 ng naloxone, when used with $0.33 \%$ plain bupivacaine for supraclavicular brachial plexus block, prolongs postoperative analgesia significantly after upper limb surgeries, without any significant side effects.

\section{KEYWORD}

Bupivacaine, naloxone, supraclavicular brachial plexus block, ultra-low dose. 


\section{INTRODUCTION}

Pain is "an unpleasant sensory and emotional experience associated with actual or potential tissue damage, or described in terms of such damage" a definition recommended by International Association for the Study of Pain (IASP) subcommittee on taxonomy. ${ }^{1}$ Prolonged pain may increase postsurgical morbidity and lead to chronic pain syndromes. In pain pathway, the regional block targets the signal traffic to the dorsal horn.

A brachial plexus block provides a useful option as an alternative to general anaesthesia in selected cases where it is possible for upper limb surgeries. The block produces a complete muscle paralysis, sympathetic block and stable hemodynamics. ${ }^{2}$ The sympathetic block is responsible to decrease postoperative pain, vasospasm and edema. Any adjunct to brachial plexus block should ideally prolong analgesia without systemic effects or prolonged motor block, and reduce the dose of local anaesthetic. Many adjuncts have been evaluated from time to time with various results, most of them being inconclusive. ${ }^{3}$ In addition to this, regional anaesthesia is considered to be safer option for the patients in terms of exposure of anaesthetic drugs and airway instrumentation, which can alter the hemodynamics significantly. Also, effective postoperative pain control can significantly reduce the morbidity of the patients and also affect the overall outcome. For this reason, effective postoperative analgesia is considered as a prerequisite to enhance recovery and decrease morbidity. ${ }^{4}$ There has been many studies to evaluate the efficacy of adjuvants like morphine, fentanyl, midazolam, clonidine and tramadol in regional block. ${ }^{5-9}$

Naloxone has been used in ultra-low dose in brachial plexus block with lidocaine resulting in prolongation of analgesia and has been safely used with epidural opioids to reduce their adverse effects. ${ }^{10-11}$ Naloxone in low doses has also been used in other nerve blocks, intravenously along with opioids in the postoperative period and with patient controlled analgesia to enhance the analgesic effects of opioids and reduce their side effects like nausea, vomiting, urinary retention and bowel dysfunction. ${ }^{12}$

In this study, we evaluated the effects of the ultra-low dose of naloxone on brachial plexus block along with local anaesthetic agent bupivacaine. The primary outcome was duration of analgesia and the secondary outcomes were onset and duration of block and comparison of adverse effects between two groups.

\section{METHODOLOGY}

Ethical approval was obtained from the Institutional Review Board of the Research Department of Institute of Medicine, Kathmandu, Nepal. All the eligible patients were evaluated prior to surgery. We included patients aged 15 to 65 years, of either sex, ASA PS I and II, weighing more than $30 \mathrm{~kg}$, presenting for surgeries at or distal to elbow, and with duration of surgery up to 3 hours. Patients who refused brachial plexus block, were not willing to undergo surgery under brachial plexus block, uncooperative, had addiction to opioids, benzodiazepines and cocaine, with history of hepatic or renal impairment, pregnant women, those who received opioids within 24 hours of surgery, hypersensitivity to the study drugs and with coagulopathy were excluded from the study. For sampling, consecutive sampling method was used, where consecutive eligible patients were enrolled over the six months duration from $1^{\text {st }}$ January to $30^{\text {th }}$ June 2012 , and were randomized into two groups. Written informed consent was obtained from 40 patients who were planned for surgeries around and below elbow joint. They were randomized into two groups by computer generated random numbers and blinding was done by Sequentially Numbered, Opaque, Sealed Envelope technique. The patients received either $29 \mathrm{ml}$ of $0.33 \%$ plain bupivacaine with $1 \mathrm{ml}$ normal saline (group BS) or $29 \mathrm{ml}$ of $0.33 \%$ plain bupivacaine with $1 \mathrm{ml}(100 \mathrm{ng}$ ) of naloxone (group BN). Study drugs were prepared by anaesthetic assistants not involved in patient care. Both the principal investigator and patients were blinded to the study drugs. After arrival in the operating theatre, standard monitors were attached for measurement of vital signs as per ASA standard (electrocardiogram, non-invasive blood pressure and pulse oximeter). Intravenous access was established and inj. Midazolam $1 \mathrm{mg}$ was administered before performing the block. Patients were kept in supine position for performance of supraclavicular brachial plexus block with head turned to contralateral side and the ipsilateral arm adducted and extended along the side towards the ipsilateral knee as far as possible. To determine the point of entry of the needle, the combination of landmarks including midpoint of clavicle, intersclaene groove and subclavian artery were identified. The point of entry was $1.5-2 \mathrm{~cm}$ posterior to mid-point of clavicle along the interscalene groove and palpating subclavian artery laterally. Aa 22 G, 2-inch blunt bevelled nerve stimulator needle (Stimuplex ${ }^{\circledR}$ B Braun) was used to localise the brachial plexus. The stimulating frequency was set at $2 \mathrm{~Hz}$, the duration of stimulus 0.1 millisecond and intensity of stimulating current starting at $3 \mathrm{~mA}$ and gradually decreased. In case of pain due to fractures, the initial current was rapidly decreased to a comfortable level. The position of the needle was considered acceptable and appropriate when a stimulating current of $0.5 \mathrm{~mA}$ or less elicited as light distal motor response. The prepared solution was injected in $5 \mathrm{ml}$ aliquots following aspiration to rule out intravascular injection. Intercostobrachial nerve blockade was performed by depositing $5 \mathrm{ml}$ of $1 \%$ lidocaine subcutaneously, superiorly and inferiorly along axillary crease with a different syringe to avoid tourniquet pain, if applied. $^{13}$

The sensory block was assessed with pinprick sensation with an atraumatic needle tip along the distribution of median, ulnar and radial nerves and compared in same areas on contralateral side. Similarly, motor block was assessed for the four nerves (musculocutaneous, radial, median and ulnar) by evaluating patient's ability to extend or flex elbow, wrist, hand or fingers and by comparing with the other side. Sensory block grading was done as grade 
$0=$ no block, grade 1 = some block and grade 2 = complete block. Similarly, motor block grading was done as grade $0=$ no block, grade $1=$ some block, grade $2=$ complete block. ${ }^{14}$ Acceptable sensory and motor block were defined as block grades of 1 or above. Midazolam was administered for sedation. In the event of failure to achieve acceptable sensory and/or motor block, the patients were administered general anaesthesia and were excluded from the study.

Assessment of pain after surgery was done using the Visual Analog Scale (VAS) at 1, 2, 4, 8 and 12 hours. ${ }^{15}$ The first dose of analgesic was administered when VAS score was more than 3 and the time of administration was noted. The total duration of sensory block was calculated as the onset of acceptable sensory block to the time of administration of first dose of post-operative analgesic.

The data were collected in preformed data collection sheet. The statistical analysis of the data was done by using SPSS software version 17. Independent t-test, Mann-Whitney $U$ test, Wilcoxon test and Chi square test were used for analysis of all variables of interest. $P$ value of less than 0.05 was considered statistically significant.

\section{RESULTS}

The patients' age, sex, weight, ASA physical status and duration of surgery were comparable in both groups (Table 1 ). Onset of acceptable sensory, motor and complete block were also comparable in both groups (Table 2). The mean duration of sensory block (analgesia) in group BN was $610.7 \pm 125.4$ minutes and the mean duration of sensory block in group BS was 354.3 \pm 59.6 minutes $(p<0.001)$. (Table 2$)$.

There were no complications noted in either group.

\begin{tabular}{|c|c|c|}
\hline Variables & Group BN & Group BS \\
\hline Age in years* & 32.5 & 26 \\
\hline Sex & $\begin{array}{c}\text { Male }=10 \\
\text { Female }=10\end{array}$ & $\begin{array}{l}\text { Male }=13 \\
\text { Female }=7\end{array}$ \\
\hline Weight $(\mathrm{kg})^{+}$ & $55.6 \pm 9.13$ & $57.8 \pm 9.01$ \\
\hline ASA PS I & 17 & 18 \\
\hline ASA PS II & 3 & 2 \\
\hline Duration of surgery (minutes) ${ }^{\dagger}$ & $95.5 \pm 32.5$ & $105.3 \pm 35.1$ \\
\hline
\end{tabular}

Table 2. Onset of sensory, motor and complete brachial plexus block and duration of analgesia

\begin{tabular}{|l|l|l|}
\hline & \multicolumn{1}{|c|}{ Group BN } & \multicolumn{1}{|c|}{ Group BS } \\
\hline Sensory Block* & $10(10,10)$ & $10(10,10)$ \\
\hline Motor Block* & $10(10,10)$ & $10(10,10)$ \\
\hline Complete Block* & $15(15,20)$ & $15(15,15)$ \\
\hline $\begin{array}{l}\text { Duration of analgesia } \\
\text { (minutes) }\end{array}$ & $610.7 \pm 125.4$ & $354.3 \pm 59.6$ \\
\hline
\end{tabular}

*= Expressed as median (Q1, Q3), Statistically not significant $\dagger=$ Expressed as Mean $\pm S D$, statistically significant $(p<0.001)$

\section{DISCUSSION}

Till date, there are only a few studies exploring the effects of naloxone on peripheral nerve blockade or epidural analgesia. ${ }^{10,11}$ Ultra-low dose naloxone has been shown to enhance antinociceptive effects of morphine when used via intravenous route. ${ }^{16}$ It has also been used in patientcontrolled analgesia (PCA) safely to enhance the potency of opioids and reduce their side effects. Our study was conducted to assess and compare the duration of analgesia in supraclavicular brachial plexus block with $0.33 \%$ plain bupivacaine with ultra-low dose of naloxone (100 ng) as an adjuvant and to assess the onset of block and any side effects. The ultra-low dose naloxone pertains to a dosing range when less than $1 \mu \mathrm{g}$ quantities of drug are used. ${ }^{17}$ In our study, we have used $100 \mathrm{ng}$ of naloxone as an adjuvant to brachial plexus block.

Our study showed that addition of an ultra-low dose (100 $\mathrm{ng}$ ) of naloxone as an adjuvant to $29 \mathrm{ml}$ of $0.33 \%$ plain bupivacaine significantly prolonged the duration of analgesia as compared to plain bupivacaine $0.33 \%$ alone. However, the median onset time were same in both groups.

These findings are comparable to a study done by Movafegh A et. al,where $100 \mathrm{ng}$ of naloxone was added to $34 \mathrm{ml} 1.5 \%$ lidocaine and $2 \mathrm{ml} 0.9 \%$ sodium chloride for brachial plexus block in the patients scheduled to undergo elective forearm surgery under axillary brachial plexus block. They found significantly prolonged duration of time to first postoperative pain $(67 \pm 7$ mins in lidocaine group vs $92 \pm 10$ mins in ultralow dose naloxone group, $\mathrm{P}<0.001){ }^{10}$

The mechanism of analgesic action of ultra-low dose naloxone is very less known. There are few proposed mechanisms by which it works, like the release of endorphins or displacement of endorphins from their binding site. It is also thought to selectively block the excitatory effects of opioids without decreasing the analgesic potency. The ultralow dose used in various studies have shown to displace ligands from their binding sites and enhance the release of endorphins which is thought to be responsible for the analgesic effects demonstrated in these studies. ${ }^{10,12}$ Similarly it may exert a paradoxical effect of analgesia by enhanced release of opioid as well as upregulation of opioid receptors. ${ }^{13}$ Also, it may exert a paradoxical effect of analgesia by enhanced release of opioid as well as upregulation of opioid receptors. ${ }^{13}$ On the molecular level, it may prevent a $\mathrm{G}$ protein coupling switch (Gi/o to $\mathrm{Gs}$ ) of the mu opioid receptor that occurs briefly after acute or persistently after chronic administration of opioids. ${ }^{18}$ Apart from all these effects, it may also exert some anti-pronociceptive effect. $^{19}$ The safety of ultra-low dose naloxone in brachial plexus block has already been established. ${ }^{10}$ Naloxone in various doses has been safely used via intravenous and epidural route as an adjunct to analgesia and to reduce the side effects of opioids. ${ }^{11,20-22}$ The dose-responsiveness of naloxone has been validated by different studies. These studies have investigated the optimal dose of naloxone additive used as an adjunct to analgesia. Based on the studies, the optimal dose of 100 nanogram would represent 
the standard dose to be used as an adjuvant in brachial plexus block. Low dose of naloxone have been shown to displace the endogenous ligands from receptor sites or release endorphins and it is possible that they exert an analgesic effect. In a study done with ultralow dose of naloxone added to ropivacaine as an adjuvant in femoral nerve block, the results showed that there was significant prolongation of postoperative analgesia without any effect on onset of sensory blockade, satisfaction and complications. ${ }^{12}$

While the opioid antagonists can cause both analgesia and hyperalgesia based on dose used, with smaller doses causing paradoxical analgesia and larger doses causing hyperalgesia in animal models, an ultra-low dose of naloxone in clinical setting has enhanced the analgesic effects of morphine. ${ }^{10}$

In our study, however, we used a fixed and single dose of naloxone. Future studies with other doses of naloxone to prove its efficacy can be reasonable as the ultra-low dose ranges from any dosing below one microgram. Also, further studies need to be done to compare naloxone with other adjuvants like clonidine and along with other local anaesthetic agents to compare the analgesic efficacy between the drugs.

\section{CONCLUSION}

In conclusion, our study has demonstrated that an ultra-low dose of naloxone (100 ng), when used with $0.33 \%$ plain bupivacaine in supraclavicular brachial plexus block significantly prolongs the duration of postoperative analgesia after upper limb surgeries at or distal to elbow, without any significant side effects.

\section{LIMITATIONS OF THE STUDY}

The major limitation of the study is that it was a single center study conducted within a limited span of time, because of which the sample size was small. It however does provide a framework for further larger multicentric studies. Besides this, only one dose of naloxone was studied. A dose finding study, exploring the effectiveness of various doses could have been imperative.

\section{ACKNOWLEDGEMENT}

None.

\section{REFERENCES}

1. Taxonomy THENOFA. Pain, 6 (1979) $247 \sim 252$ C. $1981 ; 6$ (1979): 247-52.

2. Jong RHD. Axillary blockofthebrachialplexus. Anesthesiology. 1961;22:215-25.

3. Jarbo K, Batra YK, Panda NB. Brachial plexus block with midazolam and bupivacaine improves analgesia. Can J Anesth. 2005;52(8): 822-6. PMID: 16189333.

4. Diab DG, Ramzy EA, Zaghloul HAM, Hasheesh MA. Effect of ultralow-dose naloxone during supraclavicular brachial plexus block on the antinociceptive criteria of postoperative opioid in orthopedic upper limb surgeries. Res OpinAnesth Intensive Care. 2020;7(3): 253-9.

5. Chakraborty S, Chakrabarti J, Mandal M, Hazra A, Das S. Effect of clonidine as adjuvant in bupivacaine-induced supraclavicular brachial plexus block: A randomized controlled trial. Indian J Pharmacol. 2010;42(2):74-7. PMID: 20711369.

6. Kirksey MA, Haskins SC, Cheng J, Liu SS. Local anesthetic peripheral nerve block adjuvants for prolongation of analgesia: A systematic qualitative review. PLoS One [Internet]. 2015;10(9):1-23. Available from: http://dx.doi.org/10.1371/journal.pone.0137312. PMID: 26355598.

7. Chavan SG, Koshire AR, Panbude P. Effect of addition of fentanyl to local anesthetic in brachial plexus block on duration of analgesia. Anesth Essays Res. 2011;5(1):39-42. PMID: 25885298.

8. Patil KN, Singh ND. Clonidine as an adjuvant to ropivacaine-induced supraclavicular brachial plexus block for upper limb surgeries. $J$ AnaesthesiolClinPharmacol. 2015;31(3):365-9. PMID: 26330717.

9. Shin HW, Ju BJ, Jang YK, You HS, Kang H, Park JY. Effect of tramadol as an adjuvant to local anesthetics for brachial plexus block: A systematic review and meta-analysis. PLoS One [Internet]. 2017;12(9):1-19. Available from: http://dx.doi.org/10.1371/ journal.pone.0184649. PMID: 28953949.

10. Movafegh A, Nouralishahi B, Sadeghi M, Nabavian O. An ultra-low dose of naloxone added to lidocaine or lidocaine-fentanyl mixture prolongs axillary brachial plexus blockade. AnesthAnalg. 2009;109(5):1679-83. PMID: 19843808.
11. Lee J, Shim JY, Choi JH, Kim ES, Kwon OK, Moon DE, et al. Epidural naloxone reduces intestinal hypomotility but not analgesia of epidural morphine. Can J Anesth. 2001;48(1):54-8. PMID: 11212050.

12. Lee SC, Kim JH, Choi SR, Park SY. A Low Dose of Naloxone Added to Ropivacaine Prolongs Femoral Nerve Blockade: A Randomized Clinical Trial. Pain Res Manag. 2021;2021:6639009. PMID: 33603939.

13. Joseph M. Neil YG. Cutaneous Blocks for the Upper Extremity Landmarks and Nerve Stimulator Technique.

14. Bertini L, Tagariello V, Mancini S, Ciaschi A, Posteraro CM, Benedetto P Di, et al. $0.75 \%$ and $0.5 \%$ Ropivacaine for Axillary Brachial Plexus Block : A Clinical Comparison With 0.5 \% Bupivacaine. 1999;24(6): 514-8. PMID: 10588554.

15. Haefeli M, Elfering A. Pain assessment. Eur Spine J. 2006;15(Suppl 1):S17-24. PMID: 16320034.

16. Burns L, Wang H. Ultra-Low-Dose Naloxone or Naltrexone to Improve Opioid Analgesia: The History, the Mystery and a Novel Approach. Clinical Medicine Insights: Therapeutics. 2010;2:857-68.

17. Toljan K, Vrooman B. Low-Dose Naltrexone (LDN)-Review of therapeutic utilization. Med Sci (Basel). 2018;6(4):82. PMID: 30248938.

18. Fukuda K. Miller's Anesthesia. 8th ed. Miller R, editor. New York: Churchill Livingston; 2010. 864-910p.

19. Imasogie NN, Singh S, Watson JT, Hurley D, Morley-Forster P. Ultra low-dose naloxone and tramadol/acetaminophen in elderly patients undergoing joint replacement surgery: A pilot study. Pain Res Manag. 2009;14(2):103-8. PMID: 19532850.

20. Kim MK, Nam SB, Cho MJ, Shin YS. Epidural naloxone reduces postoperative nausea and vomiting in patients receiving epidural sufentanil for postoperative analgesia. Br J Anaesth. 2007;99(2): 270-5. PMID: 17561515.

21. Hamman S, Solan PA, Witt W. Low-dose intrathecal naloxone to enhance intrathecal morphine analgesia: a case report. J Opioid Manag. 2008;4(4):251-4. PMID: 18837205.

22. Dailey PA, Brookshire GL, Shnider SM, Abboud TK, Kotelko DM, Noueihid $\mathrm{R}$, et al. The effects of naloxone associated with the intrathecal use of morphine in labor. AnesthAnalg. 1985;64 (7):658-66. PMID: 3160259. 